\title{
The Influence of Alloying Elements on the Corrosion of Zr Alloys
}

\author{
B. D. C. Bell ${ }^{\mathrm{a}}$, S. T. Murphy ${ }^{\mathrm{b}}$, P. A. Burr ${ }^{\mathrm{a}, \mathrm{c}}$, R. J. Comstock ${ }^{\mathrm{d}}$, J. M. Partezana ${ }^{\mathrm{d}}$, \\ R. W. Grimes ${ }^{a}$, M. R. Wenman* a \\ ${ }^{a}$ Department of Materials and Centre for Nuclear Engineering, Imperial College, London, SW7 2AZ, UK \\ ${ }^{b}$ Department of Physics and Astronomy, University College London, Gower Street, London, WC1E 6BT, UK \\ ${ }^{c}$ Institute of Materials Engineering, Australian Nuclear Science 8 Technology Organisation, Menai, New South \\ Wales 2234, Australia \\ ${ }^{d}$ Westinghouse Electric Company, Pittsburgh, PA 15235, USA
}

\begin{abstract}
Density functional theory (DFT) and autoclave corrosion tests in $360{ }^{\circ} \mathrm{C}$ water were used to investigate the influence of $\mathrm{Sb}, \mathrm{Sc}, \mathrm{Nb}$ and $\mathrm{Sn}$ on the corrosion and hydrogen pick-up (HPU) of Zr-alloys. Sc was shown to have a strongly detrimental effect on alloy corrosion resistance. The Nb-Sb-Zr ternary alloy exhibited significantly improved corrosion resistance over Zr-Nb and ZIRLO, and had little measurable HPU after 195 days. The ratio of $\mathrm{Sb}_{\mathrm{Zr}}^{\prime} / \mathrm{Sb}_{\mathrm{Zr}}^{\bullet}$ was shown to transition smoothly with applied space charge, implying $\mathrm{Sb}$ can act as a buffer to charge imbalance in the oxide layer.
\end{abstract}

\section{Introduction}

$\mathrm{Zr}$ is used for nuclear fuel cladding in water cooled reactors as it has good thermal and mechanical properties and a low capture cross section for thermal neutrons. Zr alloys undergo corrosion in high temperature water and steam, with rapid initial corrosion forming an oxide layer which causes the oxidation rate to slow. This is because the migration of charged species (oxygen ions and electrons) across the oxide thickness is inhibited. As corrosion progresses, a critical oxide thickness is reached at which the protection of the oxide layer breaks down and a rapid increase in oxidation rate is observed. The breakdown is known as 'transition' and is followed by a reduction in the oxidation rate as a new protective oxide layer forms. This process repeats throughout the time in the reactor (or autoclave) and the time between transitions is strongly dependent on alloy composition and microstructure $[1,2]$.

Various experimental studies have demonstrated an increased fraction of the non-equilbrium tetragonal phase close to the metal-oxide interface $[3,4,5]$, where it is stabilised by a combination of i) small grain size, ii) compressive stress (from the Pilling-Bedworth ratio of 1.56 on 
transformation from $\alpha-\mathrm{Zr}$ to $\mathrm{ZrO}_{2}$ ) and iii) the inclusion of alloying elements as dopants incorporated into the growing oxide layer $[6,7,8]$. As corrosion progresses, the metal/oxide interface (the point at which the electrochemical reaction takes place [8,9]) moves away from the newly formed oxide. The compressive stress in the oxide layer reduces significantly with distance away from the metal oxide interface [10], leading to a critical distance and thus oxide thickness where the stress is no longer sufficient to stabilise the tetragonal phase. The equilibrium phase of $\mathrm{ZrO}_{2}$, at atmospheric pressure, below $1500 \mathrm{~K}$ is monoclinic and transformation from tetragonal to monoclinic is associated with an approximately $4 \%$ volume increase in the $\mathrm{ZrO}_{2}$ unit cell [11], resulting in cracking and buckling of the oxide layer and thus a rapid increase in oxidation rate: this process is thought to be associated with the periodic transitions observed in the oxidation rate during corrosion [12]. Since it is considered to be key to corrosion behaviour of $\mathrm{Zr}$-alloys, the simulation portion of this work will focus primarily on the defect behaviour in $\mathrm{t}-\mathrm{ZrO}_{2}$.

Hydrogen is produced as water splits to form the $\mathrm{O}^{2-}$ ions required for the corrosion process, however, it has a very low solubility in $\mathrm{ZrO}_{2}$ compared to $\alpha$ - $\mathrm{Zr}$ metal [13]. Therefore, any hydrogen within the oxide layer migrates to either the cladding $\mathrm{Zr}$ metal, where it is absorbed into the cladding, or to the water. The fraction of hydrogen produced during corrosion that is absorbed into the metal, is called the hydrogen pick-up fraction (HPUF) and varies with alloy composition. It has been demonstrated that alloys with a more electrically conductive oxide layer exhibit a lower HPUF [14]. This allows electrons to move more freely though the oxide and thus allows hydrogen ion/electron recombination to occur further from the metal/oxide interface, which consequently reduces the probability of the hydrogen reaching the cladding metal [15].

Further work by Couet et al. [16] regarding the conductivity of the oxide layer has suggested that a non-equilibrium charge distribution exists in the layer. The slow diffusion of electrons and $\mathrm{V}_{\mathrm{O}}^{\bullet \bullet}{ }^{1}$, causes a charge to form within the oxide layer, resulting in an increased negative charge close to the metal oxide interface. It has been proposed that this charge (referred to as the 'space charge') is compensated by dopant species within the oxide layer; the behaviour of

\footnotetext{
${ }^{1}$ Here described in Kröger-Vink notation [17], where $\mathrm{X}_{\mathrm{Y}}^{\mathrm{Z}}$ refers to a defect atom ' $\mathrm{X}$ ' (or in the case of a vacancy ' $\mathrm{V}$ '), on a site normally occupied by ' $\mathrm{Z}$ ' (or in the case of an interstitial defect 'i') with a resulting charge of ' $\mathrm{Z}$ ' compared to the non-defective case, where ' $\mathrm{Z}$ ' can either be positive $(\bullet)$, negative $(I)$ or neutral $(\times)$. V $V_{\mathrm{O}}^{\bullet \bullet}$ refers to a vacancy on the oxygen site with a $2+$ overall charge.
} 
dopant species under an applied space charge is investigated in this work.

Alloying elements which act as oxide dopants (i.e. elements which exhibit solid solubility in both the metal and oxide) have been demonstrated to have a significant effect on the corrosion rate. Sn, for example, reduces the time between transitions in Zr-Nb-Sn alloys [18]. It has been suggested that the tendency for Sn to occupy two valence states could be a cause of this behaviour. The $\mathrm{Sn}_{\mathrm{Zr}}^{\prime \prime}$ defect is expected close to the metal/oxide interface where it is charge balanced by the increased concentration of oxygen vacancies, this increased oxygen vacancy concentration has the additional effect of helping to stabilise the tetragonal phase. Further from the metal/oxide interface, a transition to $\mathrm{Sn}_{\mathrm{Zr}}^{\times}$is expected and a consequent reduction in the concentration of tetragonal phase stabilising oxygen vacancies, thus triggering an early transition [19].

$\mathrm{Nb}$ has been shown to have a generally beneficial effect on both oxidation rate and HPUF [20, 21]. Previous investigations have concluded that the beneficial effect on corrosion performance is due to the $\mathrm{V}_{\mathrm{O}}^{\bullet \bullet}$ suppression associated with $\mathrm{Nb}_{\mathrm{Zr}}^{\bullet}$; the $\mathrm{Nb}$ defect in $\mathrm{ZrO}_{2}$ as predicted by previous DFT simulations [22]. However, experimental work [23, 24] has consistently suggested $\mathrm{Nb}$ in $\mathrm{ZrO}_{2}$ in fact occupies a range of states between 0 and $5+$, with one X-ray absorption near edge structure (XANES) study by Froideval et al. [25] unable to identify any $5+\mathrm{Nb}$ at all, thus casting doubt on the previous assumptions regarding the method by which $\mathrm{Nb}$ improves corrosion resistance and HPUF. Nb and Sn demonstrate some solid solubility in $\alpha$-Zr and so an even distribution throughout the alloy is expected; this is an important point as the current investigation considers only single and paired defects isolated in a bulk oxide and thus an even distribution of dopants in the oxide layer is assumed.

Two further elements, $\mathrm{Sb}$ and $\mathrm{Sc}$, which have not previously been used in cladding alloys are also considered. These have been chosen due to interesting properties demonstrated in previous experimental work [26, 27], and also because Sb has a solubility limit of 1.9 at. \% in $\alpha$-Zr [28] and Sc exhibits complete solid solubility in both $\alpha$ and $\beta$-Zr [29].

$\mathrm{Sb}$ has been proposed as a possible alternative (or addition to) $\mathrm{Nb}$ in low corrosion alloys, based largely on the low oxidation rate and HPUF observed in high temperature water experiments by Berry et al. [26] (the only experimental work concerning Zr-Sb alloys that could be found in the literature). Sb has the electronic structure $[\mathrm{Kr}] 4 \mathrm{~d}^{10} 5 \mathrm{~s}^{2} 5 \mathrm{p}^{3}$ and thus has two common oxidation states; $\mathrm{Sb}^{3+}$ by losing the $5 \mathrm{p}^{3}$ electrons and $\mathrm{Sb}^{5+}$ by further losing the $5 \mathrm{~s}^{2}$ 
electrons. In this it is similar to $\mathrm{Nb}$, although $\mathrm{Nb}$ can also exist in the $4+$ and $2+$ states. Given the similarities in the valence behaviour, it is hoped that insights into both $\mathrm{Nb}$ and $\mathrm{Sb}$ behaviour and the method by which they reduce corrosion and HPUF can be obtained by further studying $\mathrm{Sb}$ as an oxide dopant.

$\mathrm{Sc}$ is extremely effective at stabilising high-temperature phases of $\mathrm{ZrO}_{2}$ [30]. The oxygen vacancies required to charge balance $\mathrm{Sc}_{\mathrm{Zr}}^{\prime}$ promote vacancy stabilisation of high-temperature $\mathrm{ZrO}_{2}$ phases and also dramatically increase the oxygen ion conductivity; up to 2 orders of magnitude higher than in the commercially used yttria-stabilised $\mathrm{ZrO}_{2}$ [30]. Sc has also been used in a variety of ternary $\mathrm{Zr}$ alloys, which generally demonstrate rapid corrosion in high temperature water and steam [27], however no quantitative data regarding the oxidation behaviour of Sc-Zr alloys could be found.

Sc has the electronic structure $[\mathrm{Ar}] 3 \mathrm{~d}^{1} 4 \mathrm{~s}^{2}$ and as such shows a strong preference to form only the $3+$ charge state in $\mathrm{ZrO}_{2}$ by losing the $3 \mathrm{~d}^{1}$ and $4 \mathrm{~s}^{2}$ electrons. Therefore, investigation of a binary Zr-Sc alloy will help isolate the effect of a dopant element in a lower valence state than $\mathrm{Zr}^{4+}$. It is hoped that insights gained from investigating the behaviour of Sc will lead to a better understanding of other more useful alloying elements that can exhibit multiple valence states above, below and equal to $4+$.

In this study we use DFT based simulations to consider the behaviour of Sb and Sc as isolated defects in bulk t- $\mathrm{ZrO}_{2}$. Brouwer diagrams are generated for each alloy element under equilibrium conditions and with an applied space charge, to investigate the behaviour across a range of oxygen partial pressures, which gives information about defect concentration at various oxide layer depths. Defect clusters were also considered and the effect of co-doping t- $\mathrm{ZrO}_{2}$ was analysed. The DFT predictions were compared against oxide weight gain and HPUF measurements from autoclave corrosion experiments of $\mathrm{Zr}$ alloys containing various amounts of $\mathrm{Nb}$, Sb and Sc.

\section{Materials and Methods}

\subsection{Simulations}

Simulations were performed using the DFT code CASTEP 7.0.3 [31]. Ultra-soft pseudo potentials with a cut-off energy of $550 \mathrm{eV}$ were used throughout. The Perdew, Burke and Ernzerhof 
[32] formulation of the generalised gradient approximation was employed to describe the exchange correlation function. A Monkhorst-Pack sampling scheme [33] was used for the integration of the Brillouin Zone, with a minimum k-point separation of $0.045 \AA^{-1}$. The simulations employed density mixing using the Pulay method [34].

The energy convergence criterion for self-consistent calculations was set to $1 \times 10^{-8} \mathrm{eV}$. All simulations were performed until a maximum difference in energy of $1 \times 10^{-5} \mathrm{eV}$ and atomic displacement of $5 \times 10^{-4} \AA$ between iterations, and a maximum force between ions of $1 \times$ $10^{-2} \mathrm{eV} / \AA ̊$ was achieved.

Non-defective structures were relaxed under constant pressure to the above convergence criteria. All defective structures were generated from pre-relaxed non-defective supercells, and were energy minimised under constant volume (cell parameters constrained to maintain the shape and volume of the perfect supercell) in order to approximate dilute conditions. A supercell was formed from $3 \times 3 \times 2$ repetitions of the tetragonal $\mathrm{ZrO}_{2}$ unit cell in the $\mathrm{x}, \mathrm{y}$ and $\mathrm{z}$ directions respectively. This resulted in a 108 atom supercell, which offered a reasonable compromise between reducing finite size effects and computation time. An energy correction calculated using the Makov-Payne method [35] is used to account for the electrostatic self-interaction of defects caused by the use of periodic boundary conditions and a finite supercell size.

The defect formation energies $\left(E^{\mathrm{f}}\right)$ were calculated using the method outlined in [19]. The chemical potentials of the reactive species used to plot the Brouwer diagrams were obtained from formation energies of the relevant oxides following established methods [36, 37, 38, 39, 19].

The $E^{\mathrm{f}}$ values calculated for isolated defects were used to calculate the energy gain (-ve) or additional energy $(+\mathrm{ve})$ required to bring two isolated defects together as a defect cluster. In this case, the binding energy $\left(E_{\text {Bind }}\right)$ is defined as:

$$
E_{\mathrm{Bind}}=E_{X_{\mathrm{Zr}}^{q} Y_{\mathrm{Zr}}^{p}}^{f}-\left(E_{X_{\mathrm{Zr}}^{q}}^{f}+E_{Y_{\mathrm{Zr}}^{p}}^{f}\right)
$$

where $E_{X_{\mathrm{Zr}}^{q}}^{f}$ and $E_{Y_{\mathrm{Zr}}^{p}}^{f}$ are the formation energies of isolated defects $X$ and $Y$, each on a $\mathrm{Zr}$ site, with charges $q$ and $p$ respectively and $E_{X_{\mathrm{Zr}}^{q} Y_{\mathrm{Zr}}^{p}}^{f}$ is the formation energy of defects $X_{\mathrm{Zr}}^{q}$ and $Y_{\mathrm{Zr}}^{p}$ when placed as nearest neighbours in a supercell of $\mathrm{t}-\mathrm{ZrO}_{2}$. Relaxation volumes of neutral defect clusters were calculated from the residual stress tensor of the relaxed defect simulations 
multiplied by the bulk modulus of the perfect $\mathrm{t}-\mathrm{ZrO}_{2}$ structure, with the aid of the ANETO software package [40].

In any given defective cell, the sum of all defects each multiplied by their charge must equal zero, since there is no overall charge on the crystal. This can be expressed as follows:

$$
\sum_{i} q_{i} c_{i}-N_{\mathrm{C}} \exp \left(-\frac{E_{g}-\mu_{e}}{k_{B} T}\right)+N_{\mathrm{V}} \exp \left(-\frac{\mu_{e}}{k_{B} T}\right)=0
$$

where the first term is the sum of the charges of all ionic defects (calculated by multiplying the concentration $c$ of each defect species by its charge relative to the non-defective system $q$ ), the second term is the electron concentration and the third term the hole concentration in the crystal. $N_{c}$ and $N_{v}$ are the density of states for the conduction and valence bands, $E_{g}$ is the band gap of the crystal, $\mu_{e}$ is the electron chemical potential, $k_{B}$ is the Boltzmann constant and $T$ is the temperature. Tetragonal $\mathrm{ZrO}_{2}$ is an insulating material and so the concentrations of electrons and holes are expected to be sufficiently low that Boltzmann statistics are appropriate. The formation energy for an electron in the conduction band is slightly lower than the value calculated by $E_{g}-\mu_{e}$ due to self trapping of electrons. However, in a wide band gap insulator such as $\mathrm{ZrO}_{2}$ the difference in energy is minimal and so this is an acceptable approximation [38].

Using this relationship, the concentration of individual defects required to ensure charge neutrality (for a given set of chemical potentials and oxygen partial pressure) can be calculated. By plotting the defect concentration as a function of oxygen partial pressure a Brouwer diagram is constructed. Oxygen partial pressure in the oxide layer decreases with distance from the oxide/water interface, and thus a Brouwer diagram can give an insight into the defect concentrations through the thickness of the oxide, with the $\mathrm{x}$-axis analogous to moving with increasing $\mathrm{P}_{\mathrm{O}_{2}}$ from the metal/oxide interface (low $\mathrm{P}_{\mathrm{O}_{2}}$ ) towards the oxide/water interface (high $\mathrm{P}_{\mathrm{O}_{2}}$ ).

Recent work by Couet et al. [16] has suggested the presence of a space charge in the oxide, due to the low electron conductivity exhibited by most oxide layers. This results in a nonequilibrium electron distribution through the layer, with the high electron concentration close to the metal/oxide interface not reducing as rapidly as would be expected with distance from the interface. Conventionally, Brouwer diagrams are plotted using an equilibrium concentration of electrons, as calculated by Boltzmann statistics. In order to investigate the behaviour of defects 
under non-equilibrium conditions, a modification to the methodology was required as described below.

The space charge results in the presence of an overall negative charge in the oxide layer close to the metal oxide interface, and thus equation 2 was modified by making the sum of the charges equal to a quantity of negative charge. This negative charge is applied by including a virtual, positively charged defect into equation 2 as follows:

$$
\sum_{i} q_{i} c_{i}+q_{\mathrm{sc}}-N_{\mathrm{c}} \exp \left(-\frac{E_{g}-\mu_{e}}{k_{B} T}\right)+N_{\mathrm{V}} \exp \left(-\frac{\mu_{e}}{k_{B} T}\right)=0
$$

where $q_{\mathrm{Sc}}$ is the concentration of space charge, and for a negative space charge (as found close to the metal oxide interface) $q_{\mathrm{sc}}$ is a positive value. In a real oxide, the space charge varies across the oxide layer, and so the application of a fixed space charge term to the equation does not allow the Brouwer diagram to describe the behaviour of the defects across the full range of partial pressures. However, by fixing the space charge at a level predicted around the metal/oxide interface, it does allow an insight into the effect of space charge on the system in this region, where the space charge is most significant.

\subsection{Experimental}

In order to investigate the corrosion behaviour of $\mathrm{Sc}$ and $\mathrm{Sb}$ containing $\mathrm{Zr}$ alloys, 5 model alloys (compositions given in Table 1) were prepared for autoclave corrosion. The target amounts of each element were triple melted together into button ingots. Samples were then cut for chemical composition analysis (labelled 'Buttons' in Table 1); the carbon content was measured via combustion, the oxygen and nitrogen content via inert gas fusion (IGF) and all other elements using inductively coupled plasma optical emission spectrometry (ICP-OES).

The samples were $\beta$ annealed at $1050{ }^{\circ} \mathrm{C}$ for 10 minutes and air cooled, followed by a grit blast and pickle $\left(45 \mathrm{HNO}_{3}: 45 \mathrm{H}_{2} \mathrm{O}: 10 \mathrm{HF}\right)$ vol. \% to remove the oxide. Each button ingot was hot rolled at $280{ }^{\circ} \mathrm{C}$ in $10 \%$ reductions from an initial thickness of approximately $15 \mathrm{~mm}$ to a thickness of $3.3 \mathrm{~mm}$, followed by an air anneal at $570{ }^{\circ} \mathrm{C}\left(+/-10{ }^{\circ} \mathrm{C}\right)$ for one hour and then a further grit blast and pickle to a final thickness of $3 \mathrm{~mm}$. The alloys were then cold rolled in $10 \%$ reductions to $1.7 \mathrm{~mm}$, and subjected to a vacuum anneal at $570{ }^{\circ} \mathrm{C}$ for 1 hour. The alloys were pickled before and after the vacuum anneal such that the thickness was reduced to 
$1.5 \mathrm{~mm}$. A final cold rolling in $10 \%$ reductions was performed to a thickness of $0.8 \mathrm{~mm}$ followed by a further pickle to a thickness of $0.5 \mathrm{~mm}$. The alloys were then vacuum annealed at $570{ }^{\circ} \mathrm{C}$ for 1 hour and small samples of each alloy were removed for chemical analysis, the results of which are also presented in Table 1 (labelled 'Strips'). The ZIRLO control alloy was taken from a standard production sample, and as such was in a fully recrystallised condition with typical precipitate sizes and texture. The microstructure of the model alloys has not yet been fully characterised, however based on previous alloy preparation experience it is expected that the annealed microstructure will be fully recrystallised.

The alloys were cut into sections and placed in an autoclave containing de-ionised water at $360{ }^{\circ} \mathrm{C}$ at saturation pressure (18.67 MPa). A sample of each alloy was removed from the autoclave after 3 days, 15 days and thereafter at 15 day intervals with the latest sample removed after 105 days. The samples were dried and weighed and the hydrogen content was measured via IGF. Oxide weight gain is known to follow a power law of the form:

$$
w=A e^{n}
$$

where $w$ is the weight gain $\left(\mathrm{mg} \mathrm{dm}{ }^{-2}\right)$ and $A$ is a constant. The exponent $n$ was determined by fitting the experimental data to a power law of this form through logarithmic least squares fitting.

\section{Results and Discussion}

\section{1. $\mathrm{Sc}$ and $\mathrm{Sb}$ accommodation in $\mathrm{t}-\mathrm{ZrO}_{2}$}

The formation energies for single isolated substitutional $\mathrm{Sc}_{\mathrm{Zr}}$ and $\mathrm{Sb}_{\mathrm{Zr}}$ defects, as a function of Fermi level $\left(\mu_{e}\right)$, are shown in Figure 1. Sc $\mathrm{Zr}_{\mathrm{Zr}}^{\prime}$ is favoured across the majority of the band gap, an expected result given the propensity of $\mathrm{Sc}$ to retain an oxidation state of $3+\mathrm{Sb}$, on the other hand, exhibits a dual behaviour, with $\mathrm{Sb}_{\mathrm{Zr}}^{\bullet}$ dominant across the lower half of the band gap, and $\mathrm{Sb}_{\mathrm{Zr}}^{\prime}$ dominant at higher $\mu_{e}$ up to the conduction band minimum (CBM). The $\mathrm{Sb}_{\mathrm{Zr}}^{\bullet} / \mathrm{Sb}_{\mathrm{Zr}}^{\prime}$ transition mid way across the band gap suggests that depending on conditions, both the $\mathrm{Sb}^{3+}$ and $\mathrm{Sb}^{5+}$ defects may be observed. This property can again be explained by considering the 
Table 1: Target model alloy composition, reported composition for ZIRLO and actual measured chemistry; combustion (C), IGF (O, N) all other elements by ICP-OES. Measurements reported as '-' were not tested for as no measurable concentration was expected. Cr was tested for in the strips as contamination from the rolling process was a possibility.

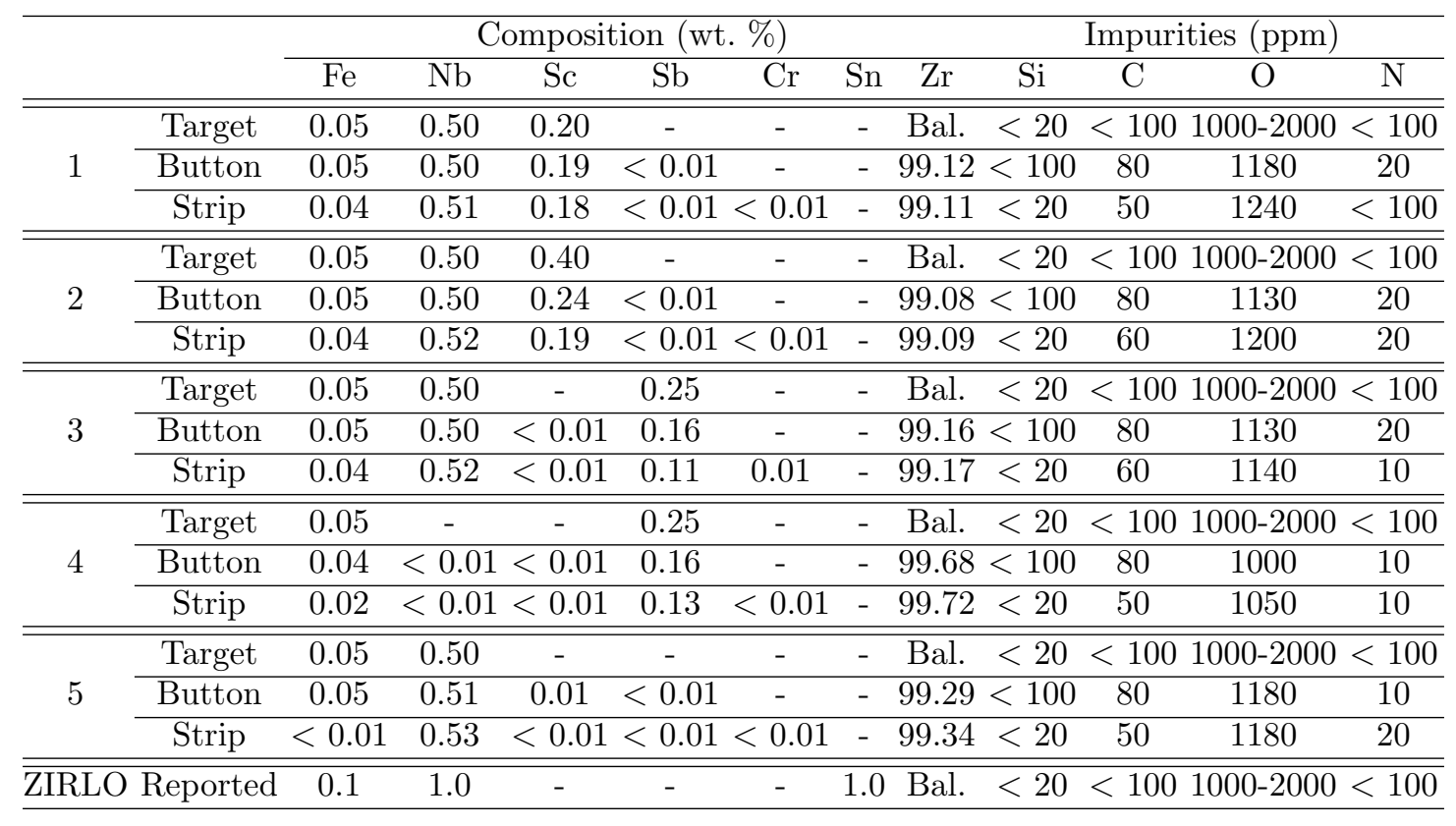

stable electronic configuration of both defects; neither have any unpaired electrons, with $\mathrm{Sb}^{3+}$ retaining the filled $5 \mathrm{~s}^{2}$ electron shell and $\mathrm{Sb}^{5+}$ retaining no valence electrons.

Brouwer diagrams were constructed for $\mathrm{t}-\mathrm{ZrO}_{2}$ containing $\mathrm{Sc}$ and $\mathrm{Sb}$ at the approximate concentrations of the Sc-Zr and Sb-Zr binary alloys listed in Table 1. Alloying element concentrations in Figures 2 and 3 are per formula unit of $\mathrm{ZrO}_{2}$. This is because concentration per formula unit of $\mathrm{ZrO}_{2}$ is the same as concentration per atom of $\mathrm{Zr}$ in the metal from which the $\mathrm{ZrO}_{2}$ was formed, allowing an easy comparison between the oxide alloying element concentration and the composition of the cladding metal. Similarly, space charge is given as electrons per formula unit of $\mathrm{ZrO}_{2}$ for ease of comparison. $1 \times 10^{-3}$ electrons per formula unit of $\mathrm{ZrO}_{2}$ is equivalent to a concentration of $2.894 \times 10^{19}$ electrons $\mathrm{cm}^{-3}$.. As in previous work [19], the Brouwer diagrams were plotted at $1500 \mathrm{~K}$, the approximate temperature at which tetragonal phase is stable under standard conditions, rather than at normal reactor operating temperature of around $600 \mathrm{~K}$, to account for the lack of stress stabilisation, in the simulations, that would normally be present in the oxide layer. 

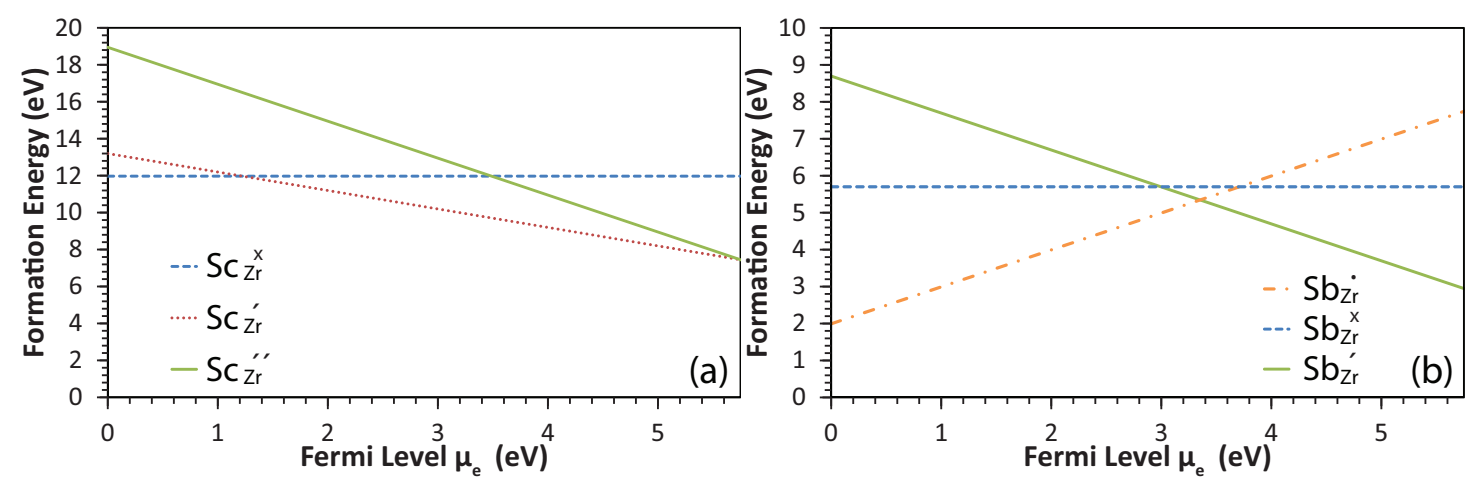

Figure 1: Formation energies of $\mathrm{Sc}(\mathrm{a})$ and $\mathrm{Sb}(\mathrm{b})$ substitutional defects as calculated by the method outlined in [19], from the valence band maximum (VBM) across the experimental band gap of $5.75 \mathrm{eV}$ [41].
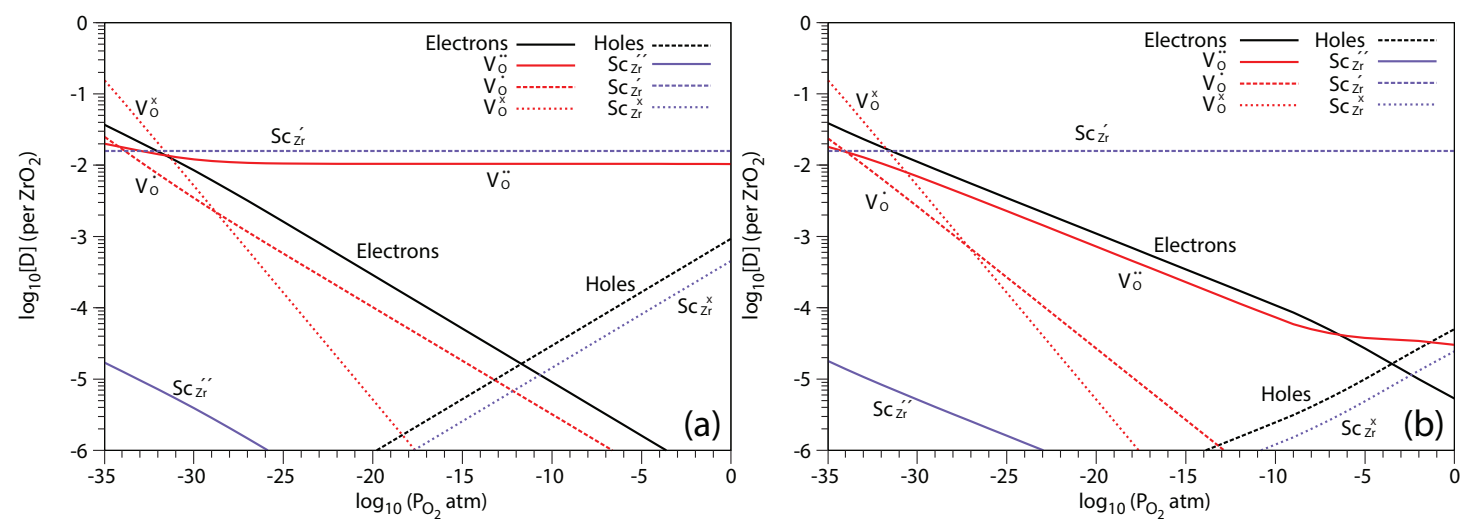

Figure 2: Brouwer diagram showing the concentrations of point defects 'D' per formula unit of $\mathrm{ZrO}_{2}$ in tetragonal $\mathrm{ZrO}_{2}$ containing $\mathrm{Sc}$ at a concentration of $2 \times 10^{-3}$ (per $\mathrm{ZrO}_{2}$ ) as a function of oxygen partial pressure at $1500 \mathrm{~K}$. (a) with no additional charge (b) applied (negative) space charge at a concentration of $1 \times 10^{-3}$ ( $\mathrm{e}^{-}$per formula unit $\mathrm{ZrO}_{2}$ ). All vacancy, substitutional and interstitial defects were considered (anti-site defects were not considered due to the large size difference between the anions and cations), however to clarify the diagrams, those with a concentration below $1 \times 10^{-6}$ were omitted. For added clarity, please refer to the online version for full colour.

Figure 2 shows that with and without the applied space charge, $\mathrm{Sc}_{\mathrm{Zr}}^{\prime}$ is strongly favoured over the alternative Sc charge states. In equilibrium conditions (Figure 2a), $\mathrm{Sc}_{\mathrm{Zr}}^{\prime}$ is dominant across the entire range of oxygen partial pressures, charge compensated by $\mathrm{V}_{\mathrm{O}}^{\bullet \bullet}$. With applied negative space charge, as expected close to the metal/oxide interface, the $\mathrm{Sc}_{\mathrm{Zr}}^{\prime}$ defect remains dominant with charged oxygen vacancies suppressed across the whole range of $\mathrm{P}_{\mathrm{O}_{2}}$. It should be noted that as mentioned in the methodology section, the applied space charge in these diagrams is constant across the whole range of $\mathrm{P}_{\mathrm{O}_{2}}$, whereas in a real oxide the charge would be expected to 
decrease towards the oxide/water interface. As previously discussed with respect to the formation energies, any $\mathrm{Sc}_{\mathrm{Zr}}$ defect other than $\mathrm{Sc}_{\mathrm{Zr}}^{\prime}$ would require an unfavoured electronic configuration and so the stability of the $\mathrm{Sc}_{\mathrm{Zr}}^{\prime}$ even with a very high concentration of applied space charge was expected.
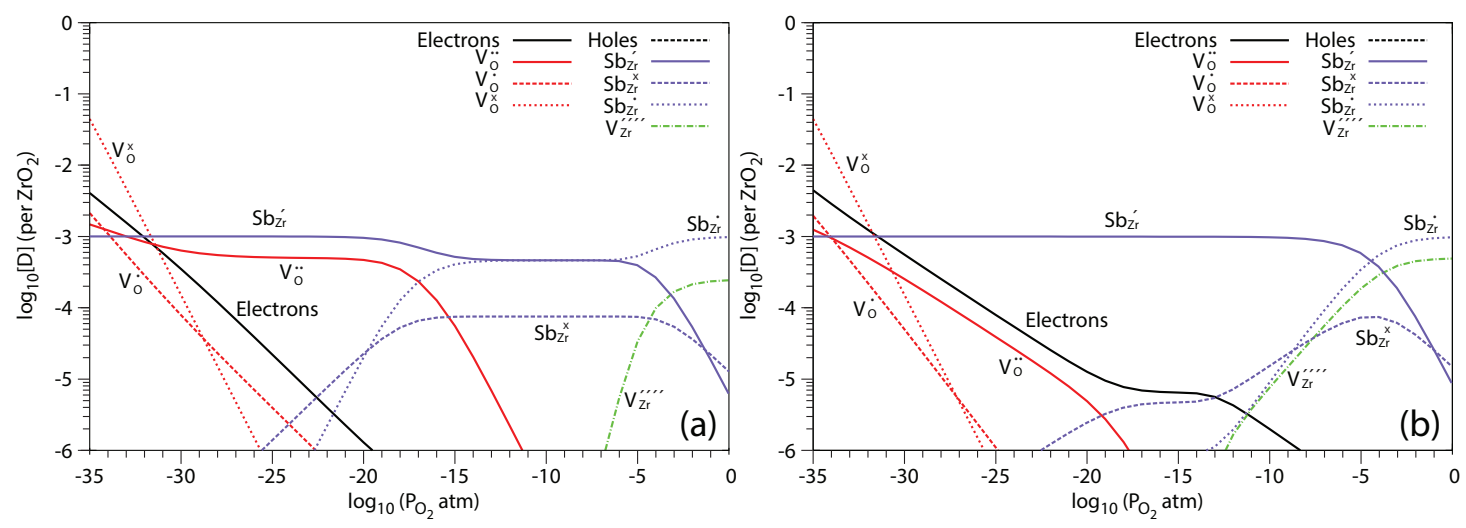

Figure 3: Brouwer diagram showing the concentrations of point defects in $\mathrm{t}-\mathrm{ZrO}_{2}$ containing $\mathrm{Sb}$ at a concentration of $1 \times 10^{-3}$ (per $\mathrm{ZrO}_{2}$ ) as a function of oxygen partial pressure at $1500 \mathrm{~K}$, (a) with no additional charge and (b) applied space charge at a concentration of $1 \times 10^{-3}\left(\mathrm{e}^{-}\right.$per $\left.\mathrm{ZrO}_{2}\right)$. For added clarity, please refer to the online version for full colour.

Figure $3 \mathrm{a}$ shows that at oxygen partial pressures below $10^{-15}$ atm, in equilibrium conditions, $\mathrm{Sb}_{\mathrm{Zr}}^{\prime}$ is dominant and is charge compensated by $\mathrm{V}_{\mathrm{O}}^{\bullet \bullet}$. At oxygen partial pressures between $10^{-15}$ and $10^{-5} \mathrm{~atm}, \mathrm{Sb}_{\mathrm{Zr}}^{\prime}$ and $\mathrm{Sb}_{\mathrm{Zr}}^{\bullet}$ co-exist in roughly equal concentrations, with $\mathrm{Sb}_{\mathrm{Zr}}^{\bullet}$ becoming dominant above $10^{-5}$ atm and $\mathrm{Sb}_{\mathrm{Zr}}^{\prime}$, charge compensated by $\mathrm{V}_{\mathrm{Zr}}^{\prime \prime \prime \prime}$. Figure $3 \mathrm{~b}$ shows that as space charge is applied, the $\mathrm{P}_{\mathrm{O}_{2}}$ regime of coexistence vanishes, and the $\mathrm{Sb}_{\mathrm{Zr}}^{\prime} / \mathrm{Sb}_{\mathrm{Zr}}^{\bullet}$ transition occurs relatively sharply at around $10^{-5}$ atm. A plot of the partial pressure at which the crossover from $\mathrm{Sb}_{\mathrm{Zr}}^{\prime}$ to $\mathrm{Sb}_{\mathrm{Zr}}^{\bullet}$ as the dominant defect occurs, as a function of applied space charge, is provided in Figure 4, with the transition from $\mathrm{Sn}_{\mathrm{Zr}}^{\prime \prime}$ to $\mathrm{Sn}_{\mathrm{Zr}}^{\times}$[19] shown for comparison. It demonstrates that $\mathrm{Sb}_{\mathrm{Zr}}$ exhibits a constant crossover $\mathrm{P}_{\mathrm{O}_{2}}$, up to a space charge concentration of around $1 \times 10^{-7}$ (e per $\mathrm{ZrO}_{2}$ ) and then a linear increase in $\mathrm{P}_{\mathrm{O}_{2}}$ as the applied space charge increases further. This behaviour is in stark contrast to previous predictions for $\mathrm{Sn}_{\mathrm{Zr}}$ [19], in which the $\mathrm{Sn}_{\mathrm{Zr}}^{\prime \prime}$ to $\mathrm{Sn}_{\mathrm{Zr}}^{\times}$crossover remains constant until a critical applied charge is reached, at which point there was an abrupt change of 10 orders of magnitude in the crossover partial pressure. The linear behaviour of the $\mathrm{Sb}_{\mathrm{Zr}}^{\prime} / \mathrm{Sb}_{\mathrm{Zr}}^{\bullet}$ transition suggests that in the $\mathrm{P}_{\mathrm{O}_{2}}$ regime of 
$10^{-15}-10^{-5} \mathrm{~atm}$, of this defect, $\mathrm{Sb}_{\mathrm{Zr}}$ acts as a buffer to applied charge, whether in the form of space charge or additional charged defects. Furthermore, the $\mathrm{Sb}_{\mathrm{Zr}}^{\prime} / \mathrm{Sb}_{\mathrm{Zr}}^{\bullet}$ transition happens much further away from the metal oxide interface than the $\mathrm{Sn}_{\mathrm{Zr}}^{\prime \prime} / \mathrm{Sn}_{\mathrm{Zr}}^{\times}$transition. It has been suggested that the loss of oxygen vacancy stabilisation caused by the transformation from $\mathrm{Sn}_{\mathrm{Zr}}^{\prime \prime}$ to $\mathrm{Sn}_{\mathrm{Zr}}^{\times}$ may be responsible for the early breakaway corrosion observed in Sn containing alloys [19], and while this effect may also occur in Sb containing alloys, the greater distance from the metal oxide interface is likely to reduce the effect of tetragonal phase destabilisation in triggering breakaway corrosion.

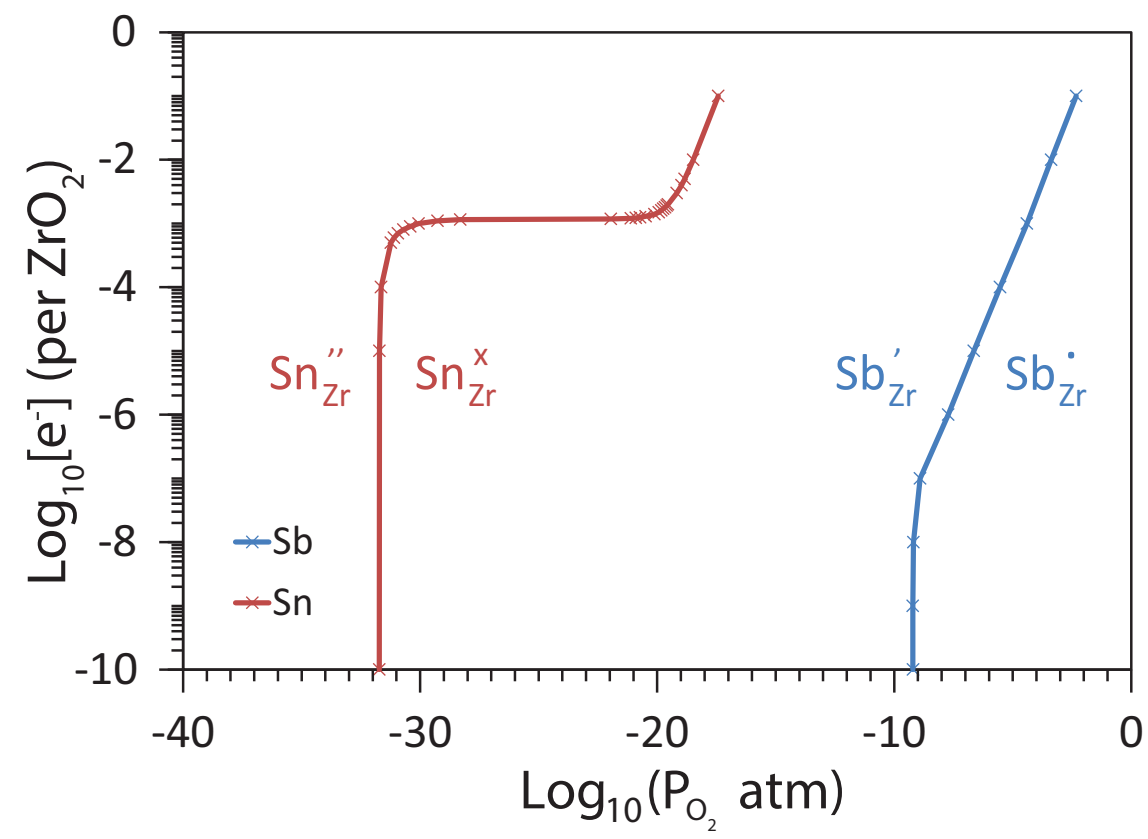

Figure 4: A plot showing the oxygen partial pressure at which the $\mathrm{Sb}_{\mathrm{Zr}}^{\prime} / \mathrm{Sb}_{\mathrm{Zr}}^{\bullet}$ transition occurs as a function of the applied space charge (in units of electrons per formula unit of $\mathrm{ZrO}_{2}$ ), Sn data from [19].

\subsection{Alloy corrosion and HPUF}

Figure 5 shows the weight gain and hydrogen pick up of alloy 3 (Zr-0.5Nb-0.1Sb), alloy 5 (Zr-0.5Nb) and a sample of ZIRLO. The alloys containing Sc (1 and 2) are not shown as they exhibited extremely fast corrosion, with both alloy samples oxidising completely within 3 days. The Zr-0.1Sb alloy (4) is also not plotted as it underwent a first transition between 30 and 45 days (30 day average weight gain was $33.2 \mathrm{mg} \mathrm{dm}^{-2}, 45$ days was $166.7 \mathrm{mg} \mathrm{dm}^{-2}$ ) and proceeded 
to oxidise rapidly, with an average oxide weight gain of $515 \mathrm{mg} \mathrm{dm}^{-2}$ after 105 days (i.e. over an order of magnitude higher than the alloys shown in Figure 5).

Sc is included as a $\mathrm{ZrO}_{2}$ dopant in solid oxide fuel cells to stabilise the high temperature tetragonal and cubic phases for use as a solid electrolyte. By incorporating $\mathrm{O}$ vacancies into the structure as charge compensation for the $\mathrm{Sc}_{\mathrm{Zr}}^{\prime}$ defect, the $\mathrm{O}$ ion conductivity of the high temperature phases increases dramatically [30]. As shown in Figure 2a, oxygen vacancies are the main charge compensation mechanism for the dominant $\mathrm{Sc}_{\mathrm{Zr}}^{\prime}$ defect, suggesting that a similar process is likely to occur in the oxide layer of Sc containing alloys. The enhanced $\mathrm{O}$ ion conductivity is the reason suggested for the significant increase in corrosion rate observed when compared to non-Sc containing alloys and an increased vacancy-stabilised tetragonal phase fraction (as observed in Sn containing alloys [18]) is expected. The rapid oxidation into a $\mathrm{ZrO}_{2}$ powder prevented the measurement of hydrogen content in the Sc containing alloys.

The Sb-Zr binary alloy exhibited a significantly higher corrosion rate than the Nb-Zr binary alloy. Figure 3 suggests that $\mathrm{Sb}_{\mathrm{Zr}}^{\prime}$ is the dominant defect across the majority of oxygen partial pressures, charge balanced by oxygen vacancies. As previously discussed for Sc, an increased oxygen vacancy concentration generally results in increased oxygen conductivity through the oxide layer, and thus a higher oxidation rate is perhaps expected in an Sb-Zr binary alloy. The hydrogen content remained at a constant $15 \mathrm{ppm}$ pre-transition, with a rapid linear increase measured after the first transition at 30 days to a final average measurement of $578 \mathrm{ppm}$ after 105 days.

The Sb-Nb-Zr ternary alloy (3) showed a slightly lower corrosion rate than both the NbZr binary alloy (5) and the pre-transition ZIRLO sample, with the ZIRLO sample exhibiting evidence of passing through first transition after around 90 days (see Figure 5a). It should be noted that the fitted lines for the data points from alloy 3 and ZIRLO had very similar exponents (0.40 and 0.37 respectively). There was very little measurable hydrogen pick up by alloys 3 and 5 through the duration of the corrosion with both exhibiting approximately the same hydrogen content after 195 days as in the pre-corrosion measurements. This contrasts with the ZIRLO control sample, which showed a steady increase in hydrogen content throughout corrosion, with a slight acceleration in pick-up rate after 90 days, coinciding with the first transition indicated by the weight gain results. This would be consistent with the proposition that $\mathrm{Sb}$ in conjunction 
with $\mathrm{Nb}$ acts to improve the corrosion resistance of the alloys better than either element in isolation, although this assumes a similar microstructure and precipitate size and distribution between the two model alloys, a property that has not yet been investigated. Also, since the final measured $\mathrm{Sb}$ content of 0.1 at. \% was significantly lower than the target composition and at such a small concentration, it is difficult to be certain the observed results can be attributed to the behaviour of $\mathrm{Sb}$ as an oxide dopant.
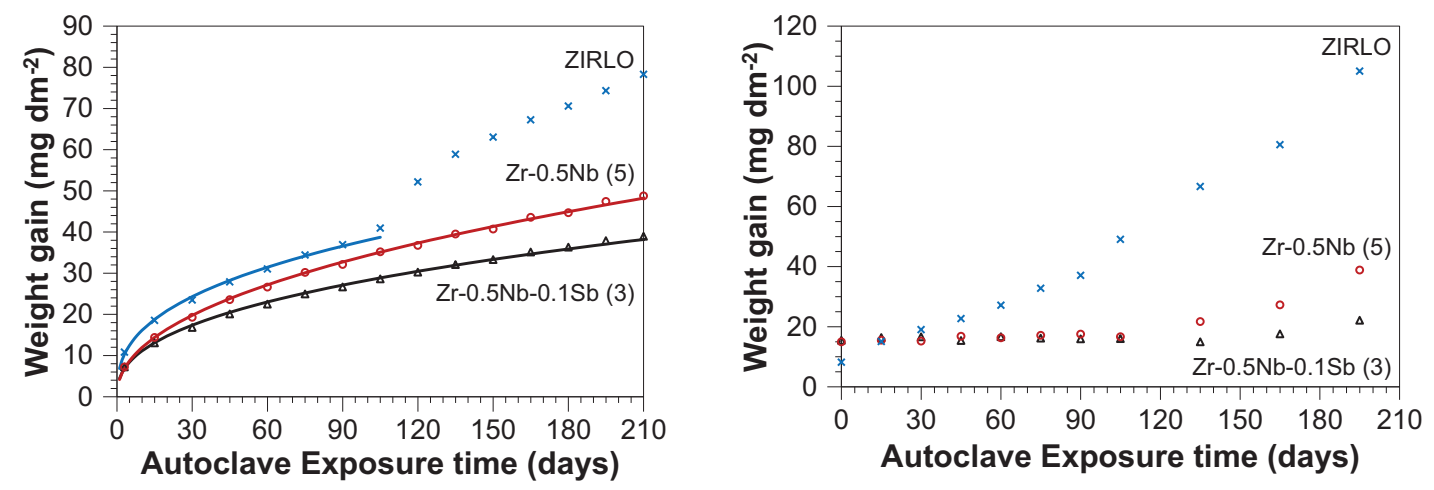

Figure 5: Graphs showing (a) the oxide weight gain and (b) hydrogen pick up of alloys 3,5 and the control alloy (ZIRLO). Error bars are not shown since the standard deviation was no higher than $0.4 \mathrm{mg} \mathrm{dm}{ }^{-2}$ for any point shown on graph (a) with 4-6 samples measured per data point. The data points were fitted to Equation 4 yielding the trend lines shown in (a). The exponents for the fitted lines were: alloy $3 n=0.40$, alloy $5 n=0.46$, ZIRLO (control) $n=0.37$. The points for the ZIRLO weight gain after 105 days were not included in the fit as the alloy has passed through transition.

\subsection{Defect clusters}

Using Equation 1, the binding energies of the most energetically favourable neutral defect clusters composed of $\mathrm{Nb}, \mathrm{Sc}, \mathrm{Sb}$ and $\mathrm{Sn}$ are reported in Table 2. As expected, $\mathrm{Sc}_{\mathrm{Zr}}$ is in the $3+$ charge state in all clusters, pushing the other defects to assume higher oxidation states to retain overall charge neutrality. The $\mathrm{Nb}-\mathrm{Sc}$ defect cluster has an unfavourable binding energy of $+0.23 \mathrm{eV}$ suggesting a driving force against association (clustering). This is significant, as experimental and theoretical work has suggested that $\mathrm{Sc}_{\mathrm{Zr}}$ defects tend to form $\left\{\mathrm{V}_{\mathrm{O}}^{\bullet \bullet}: 2 \mathrm{Sc}_{\mathrm{Zr}}^{\prime}\right\}^{\times}$ neutral clusters [30]. Prior to the casting of the alloys, it was expected that the presence of $\mathrm{Nb}$ would help to mitigate the increase in corrosion rate expected from the inclusion of Sc as an alloying element. Both Sc containing alloys (Sc-Zr binary and Sc-Nb-Zr ternary) oxidised completely within 3 days of autoclave corrosion, implying that the $\mathrm{Nb}$ did little to improve the corrosion resistance. The defect cluster formation energies may offer an explanation; in order to 
charge balance $\mathrm{Sc}_{\mathrm{Zr}}^{\prime}$ and prevent the formation of the $\left\{\mathrm{V}_{\mathrm{O}}^{\bullet \bullet}: 2 \mathrm{Sc}_{\mathrm{Zr}}^{\prime}\right\}^{\times}$defect cluster, $\mathrm{Nb}_{\mathrm{Zr}}^{\bullet}$ would have to be on an adjacent $\mathrm{Zr}$ site, which as reported in Table 2, is an energetically unfavourable arrangement. This implies that despite the presence of $\mathrm{Nb}$ in the oxide layer, the Sc-Nb-Zr alloy still contains areas with increased oxygen vacancy concentration, with $\mathrm{Nb}$ suppressing oxygen vacancy concentration elsewhere.

The Sb-Sc cluster exhibited a favourable binding energy of -0.19 eV, implying that Sb may be able to mitigate the increased corrosion effects that would otherwise be expected in Sc-containing alloys. Both the $\mathrm{Sb}-\mathrm{Sb}$ and $\mathrm{Nb}-\mathrm{Nb}$ clusters were also favourable, with similar binding energies of $-0.19 \mathrm{eV}$ and $-0.17 \mathrm{eV}$ respectively. The neutral $\mathrm{Sb}-\mathrm{Sb}$ cluster preferred to exist as $\mathrm{Sb}_{\mathrm{Zr}^{-}}^{\prime}$ $\mathrm{Sb}_{\mathrm{Zr}}^{\bullet}$, however the neutral Nb-Nb cluster favoured existing as $\mathrm{Nb}_{Z r}^{\times}-\mathrm{Nb}_{Z r}^{\times}$. These results are particularly interesting as they may possibly contradict previous assumptions that $\mathrm{Nb}_{\mathrm{Zr}}^{\bullet}$ is the preferred charge state for $\mathrm{Nb}_{Z r}$ in $\mathrm{ZrO}_{2}$.

The relaxation volumes were calculated using the methodology detailed in Section 2.1 and are reported in Table 2. There appears to be little correlation between the defect volumes and the calculated binding energies, suggesting that electronic interactions of ions are dominant over strain effects (due to the size of ions) in determining the binding energy of the clusters investigated.

Table 2: Binding energies and calculated defect volumes of the most energetically favourable neutral defect clusters containing two cations, calculated using Equation 1.

\begin{tabular}{cccc}
\hline \multicolumn{2}{c}{ Cluster } & $E_{\text {Bind }}(\mathrm{eV})$ & Relaxation Volume $\left(\AA^{3}\right)$ \\
\hline \hline $\mathrm{Nb}_{\mathrm{Zr}}^{\circ}$ & $\mathrm{Sb}_{\mathrm{Zr}}^{\prime}$ & +0.22 & 6.88 \\
\hline $\mathrm{Sb}_{\mathrm{Zr}}^{\prime}$ & $\mathrm{Sb}_{\mathrm{Zr}}^{\bullet}$ & -0.16 & 14.12 \\
\hline $\mathrm{Sc}_{\mathrm{Zr}}^{\prime}$ & $\mathrm{Sb}_{\mathrm{Zr}}^{\bullet}$ & -0.19 & 3.40 \\
\hline $\mathrm{Nb}_{\mathrm{Zr}}^{\times}$ & $\mathrm{Nb}_{\mathrm{Zr}}^{\times}$ & -0.17 & -1.91 \\
\hline $\mathrm{Sc}_{\mathrm{Zr}}^{\prime}$ & $\mathrm{Nb}_{\mathrm{Zr}}^{\bullet}$ & +0.23 & -2.11 \\
\hline $\mathrm{Nb}_{\mathrm{Zr}}^{\times}$ & $\mathrm{Sn}_{\mathrm{Zr}}^{\times}$ & -0.13 & 1.47 \\
\hline
\end{tabular}

\section{Conclusions}

1. Sc was shown to assume the $3+$ charge state $\left(\mathrm{Sc}_{\mathrm{Zr}}^{\prime}\right)$ compensated by $\mathrm{V}_{\mathrm{O}}^{\bullet \bullet}$ across all oxygen partial pressures $\left(10^{-35}-10^{0} \mathrm{~atm}\right)$, even under applied space charge at a concentration of $1 \times$ 
$10^{-3} e^{-}$per formula unit $\mathrm{ZrO}_{2}$.

2. At $\mathrm{P}_{\mathrm{O}_{2}}$ between $10^{-15}$ and $10^{-5}$ atm the $\mathrm{Sb}_{\mathrm{Zr}}^{\prime}$ and $\mathrm{Sb}_{\mathrm{Zr}}^{\bullet}$ defects are predicted to coexist in roughly equal concentrations, with $\mathrm{Sb}_{\mathrm{Zr}}^{\bullet}$ becoming dominant above $10^{-5} \mathrm{~atm}$. Applied space charge caused the concentrations of $\mathrm{Sb}_{\mathrm{Zr}}^{\prime}$ and $\mathrm{Sb}_{\mathrm{Zr}}^{\bullet}$ to change, compensating for the nonequilibrium charge. This implies that Sb may act as a buffer to applied charge in the oxide layer.

3. The Sc-Nb-Zr alloys corroded very rapidly in the autoclave.

4. The Sb-Zr binary alloy demonstrated significant corrosion, however Sb loss during alloy fabrication resulted in the $\mathrm{Sb}$ content in the tested alloys being significantly below the target and as such it is not possible to say with confidence that Sb cannot promote corrosion resistance in Zr-based alloys.

5. The Zr-Nb alloy performed as expected, exhibiting a low corrosion rate and low hydrogen pickup.

6. The Zr-Nb-Sb ternary alloy exhibited the lowest corrosion rate and almost no measurable hydrogen pick-up for the duration of autoclave corrosion.

\section{Acknowledgements}

Bell, Grimes and Wenman would like to acknowledge Rolls-Royce for the financial support for the modelling work as part of the Westinghouse led MUZIC-2 research programme and for the computational resources provided by the Imperial College High Performance Computing Centre.

[1] E. Hillner, Corrosion of Zirconium-Base Alloys - An Overview, Zirconium in the Nuclear Industry: Proceedings of the Third International Conference (1977) 211235doi:10.1520/STP35573S.

[2] J. S. Bryner, The cyclic nature of corrosion of Zircaloy-4 in $633 \mathrm{~K}$ water, Journal of Nuclear Materials 82 (1979) 84-101. doi:10.1016/0022-3115(79)90042-4.

[3] H. J. Beie, Examinations of the corrosion mechanism of zirconium alloys, Zirconium in the Nuclear Industry: Tenth International Symposium (1993) 615-643doi:10.1520/STP15212S.

[4] M. Preuss, P. Frankel, S. Lozano-Perez, D. Hudson, E. Polatidis, N. Ni, J. Wei, C. English, S. Storer, K. B. Chong, M. Fitzpatrick, P. Wang, J. Smith, C. Grovenor, G. Smith, J. Sykes, B. Cottis, S. Lyon, L. Hallstadius, B. Comstock, A. Ambard, M. Blat-Yrieix, P. Barberis, S. W. Dean, Studies regarding corrosion mechanisms in zirconium alloys, Journal of ASTM International 8 (9) (2011) 649-681. doi:10.1520/JAI103246. 
[5] A. Garner, M. Preuss, P. Frankel, A method for accurate texture determination of thin oxide films by glancing-angle laboratory X-ray diffraction, Journal of Applied Crystallography 47 (2) (2014) 575-583. doi:10.1107/S1600576714000569.

[6] Y. Ding, D. O. Northwood, TEM study of the oxide-metal interface formed during corrosion of Zr-2.5 wt.\% Nb pressure tubing, Materials Characterization 30 (1) (1993) 13-22. doi:10.1016/1044-5803(93)90004-F.

[7] N. Petigny, P. Barberis, C. Lemaignan, C. Valot, M. Lallemant, In situ XRD analysis of the oxide layers formed by oxidation at $743 \mathrm{~K}$ on Zircaloy 4 and $\mathrm{Zr}-1 \mathrm{NbO}$, Journal of Nuclear Materials 280 (3) (2000) 318-330. doi:10.1016/S0022-3115(00)00051-9.

[8] A. Yilmazbayhan, A. T. Motta, R. J. Comstock, G. P. Sabol, B. Lai, Z. Cai, Structure of zirconium alloy oxides formed in pure water studied with synchrotron radiation and optical microscopy: relation to corrosion rate, Journal of Nuclear Materials 324 (1) (2004) 6-22. doi:10.1016/j.jnucmat.2003.08.038.

[9] A. Ly, A. Ambard, M. Blat-Yrieix, L. Legras, P. Frankel, M. Preuss, C. Curfs, G. Parry, Y. Brechet, P. Barberis, S. W. Dean, Understanding Crack Formation at the Metal/Oxide Interface During Corrosion of Zircaloy-4 Using a Simple Mechanical Model, Journal of ASTM International 8 (9) (2011) 103550. doi:10.1520/JAI103550.

[10] E. Polatidis, P. Frankel, J. Wei, M. Klaus, R. J. Comstock, A. Ambard, S. Lyon, R. A. Cottis, M. Preuss, Residual stresses and tetragonal phase fraction characterisation of corrosion tested Zircaloy-4 using energy dispersive synchrotron X-ray diffraction, Journal of Nuclear Materials 432 (1-3) (2013) 102-112. doi:10.1016/j.jnucmat.2012.07.025.

[11] J. Dewhurst, J. Lowther, Relative stability, structure, and elastic properties of several phases of pure zirconia, Physical Review B 57 (2) (1998) 741-747. doi:10.1103/PhysRevB.57.741.

[12] H. Anada, K. Takeda, Microstructure of oxides on Zircaloy-4, 1.0 Nb Zircaloy-4, and Zircaloy-2 formed in 10.3-MPa steam at $673 \mathrm{~K}$, Zirconium in the Nuclear Industry: Eleventh International Symposium (1996) 35-54doi:10.1520/STP16166S.

[13] M. Miyake, M. Uno, S. Yamanaka, On the zirconium - oxygen - hydrogen ternary system, Journal of Nuclear Materials 270 (1999) 233-241. doi:10.1016/S0022-3115(98)00779-X.

[14] H. Gohr, J. Schaller, H. Ruhmann, F. Garzarolli, Long-term In Situ Corrosion Investigation of Zr Alloys in Simulated PWR Environment by Electrochemical Measurements, Zirconium in the Nuclear Industry: 11th International Symposium, ASTM STP 1295 (1996) 181202doi:10.1520/STP16173S.

[15] A. Couet, A. T. Motta, R. J. Comstock, Effect of alloying elements on hydrogen pick-up in zirconium alloys, Zirconium in the Nuclear Industry: 17th International Symposium, ASTM STP 1543 (2013) 479-514doi:10.1520/STP154320120215.

[16] A. Couet, A. T. Motta, A. Ambard, The coupled current charge compensation model for zirconium alloy fuel cladding oxidation: I. Parabolic oxidation of zirconium alloys, Corrosion Sciencedoi:10.1016/j.corsci.2015.07.003.

[17] F. A. Kroger, H. J. Vink, Relations between the concentrations of imperfections in crystalline solids, Solid State Physics 3 (1956) 307-435. doi:10.1016/0022-3697(58)90069-6. 
[18] J. Wei, P. Frankel, E. Polatidis, M. Blat, A. Ambard, R. Comstock, L. Hallstadius, D. Hudson, G. Smith, C. R. M. Grovenor, M. Klaus, R. A. Cottis, S. Lyon, M. Preuss, The effect of Sn on autoclave corrosion performance and corrosion mechanisms in $\mathrm{Zr}-\mathrm{Sn}-\mathrm{Nb}$ alloys, Acta Materialia 61 (11) (2013) 4200-4214. doi:10.1016/j.actamat.2013.03.046.

[19] B. D. C. Bell, S. T. Murphy, P. A. Burr, R. W. Grimes, M. R. Wenman, Accommodation of tin in tetragonal ZrO2, Journal of Applied Physics 117 (2015) 084901. doi:10.1063/1.4909505.

[20] A. Yilmazbayhan, M. Gomes, A. Motta, H. G. Kim, Y. H. Jeong, J. Y. Park, R. Comstock, B. Lai, Z. Cai, Characterisation of oxides formed on model zirconium alloys in 360 $\mathrm{C}$ water using micro-beam synchrotron radiation, in: Proceedings of the 12 th International Conference on Environmental Degradation of Materials in Nuclear Power System - Water Reactors, Salt Lake City, UT, 2005, p. 201.

[21] A. Yilmazbayhan, E. Breval, A. T. Motta, R. J. Comstock, Transmission electron microscopy examination of oxide layers formed on Zr alloys, Journal of Nuclear Materials 349 (3) (2006) 265-281. doi:10.1016/j.jnucmat.2005.10.012.

[22] U. Otgonbaatar, W. Ma, Effect of Niobium on the Defect Chemistry and Oxidation Kinetics of tetragonal ZrO2, Journal of Physical Chemistry C 118 (35) (2014) 20122-20131. doi:10.1021/.jp504874v.

[23] K. Sakamoto, K. Une, M. Aomi, K. Hashizume, Oxidation Behaviour of Niobium in Oxide Layer of Zirconium-Niobium Alloys, in: TopFuel, Manchester, UK, 2012, pp. 297-306.

[24] K. Sakamoto, K. Une, M. Aomi, T. Otsuka, K. Hashizume, Change of chemical states of niobium in the oxide layer of zirconium-niobium alloys with oxide growth, Journal of Nuclear Science and Technology (July 2015) (2015) 1-6. doi:10.1080/00223131.2015.1058196.

[25] A. Froideval, C. Degueldre, C. Segre, M. Pouchon, D. Grolimund, Niobium speciation at the metal/oxide interface of corroded niobium-doped Zircaloys: A X-ray absorption near-edge structure study, Corrosion Science 50 (5) (2008) 1313-1320. doi:10.1016/j.corsci.2008.01.011.

[26] W. E. Berry, D. A. Vaughan, E. L. White, Hydrogen Pickup During Aqueous Corrosion of Zirconium Alloys, Corrosion 17 (3) (1961) 109t-117t. doi:10.5006/0010-9312-17.3.81.

[27] R. D. Misch, C. Van Drunen, Corrosion Studies of Ternary Zirconium Alloys in HighTemperature Water and Steam, Tech. Rep. July 1961, Argonne National Laboratory, Argonne, Illinois (1961). doi:10.2172/4834895.

[28] H. Okamoto, The Sb-Zr (antimony-zirconium) system, Journal of Phase Equilibria 14 (2) (1993) 228-231. doi:10.1007/BF02667815.

[29] A. Palenzona, S. Cirafici, The Sc-Zr (Scandium-Zirconium) System, Journal of Phase Equilibria 12 (1) (1991) 53-56. doi:10.1007/BF02663675.

[30] N. Kim, C. H. Hsieh, J. F. Stebbins, Scandium coordination in solid oxides and stabilized zirconia: 45Sc NMR, Chemistry of Materials 18 (16) (2006) 3855-3859. doi:10.1021/cm0605901.

[31] S. J. Clark, M. D. Segall, First principles methods using CASTEP, Zeitschrift fur Kristallographie 220 (2005) 567-570. doi:10.1524/zkri.220.5.567.65075. 
[32] J. Perdew, K. Burke, M. Ernzerhof, Generalized Gradient Approximation Made Simple., Physical Review Letters 77 (18) (1996) 3865-3868. doi:http://dx.doi.org/10.1103/PhysRevLett.77.3865.

[33] H. J. Monkhorst, J. D. Pack, Special points for Brillouin-zone integrations, Physical Review B 13 (12) (1976) 5188-5192. doi:10.1103/PhysRevB.13.5188.

[34] P. Pulay, Convergence Acceleration of Iterative Sequences. The Case of SCF Iteration, Chemical Physical Letters 73 (2) (1980) 393-398. doi:10.1016/0009-2614(80)80396-4.

[35] G. Makov, M. Payne, Periodic boundary conditions in ab initio calculations, Physical Review Bdoi:10.1103/PhysRevB.51.4014.

[36] M. W. Finnis, A. Y. Lozovoi, A. Alavi, The Oxidation of NiAl: What Can We Learn from Ab Initio Calculations?, Annual Review of Materials Research 35 (1) (2005) 167-207. doi:10.1146/annurev.matsci.35.101503.091652.

[37] H. A. Tahini, A. Chroneos, S. T. Murphy, U. Schwingenschloogl, R. W. Grimes, Vacancies and defect levels in III-V semiconductors, Journal of Applied Physics 114 (6) (2013) 063517. doi:10.1063/1.4818484.

[38] S. T. Murphy, M. W. D. Cooper, R. W. Grimes, Point defects and non-stoichiometry in thoria, Solid State Ionics 267 (2014) 80-87. doi:10.1016/j.ssi.2014.09.017.

[39] S. T. Murphy, N. D. M. Hine, Point defects and non-stoichiometry in Li 2 TiO 3, Chemistry of Materials 26 (4) (2014) 1629-1638. doi:10.1021/cm4038473.

[40] C. Varvenne, F. Bruneval, M. C. Marinica, E. Clouet, Point defect modeling in materials: Coupling ab initio and elasticity approaches, Physical Review B - Condensed Matter and Materials Physics 88 (13) (2013) 1-7. doi:10.1103/PhysRevB.88.134102.

[41] R. H. French, S. J. Glass, F. S. Ohuchi, Y. N. Xu, W. Y. Ching, Experimental and theoretical determination of the electronic structure and optical properties of three phases of $\mathrm{ZrO} 2$, Physical Review B 49 (8). doi:10.1103/PhysRevB.49.5133. 